\title{
A incompletude do homem na perspectiva do axolotl
}

Ana Carolina Cernicchiaro

Doutoranda em Literatura / UFSC, com bolsa do CNPq

\begin{abstract}
RESUMO
Em sua entrega ao ponto de vista do outro, na transmutação de perspectivas, no devir-animal do homem e no devir-homem do animal, o conto "Axolotl”, de Julio Cortázar, coloca em questão as dicotomias identitárias e estanques da humanidade e revela nossa incompletude, o ser-com que somos, o eu como um devir entre multiplicidades.
\end{abstract}

\section{PALAVRAS-CHAVE}

Axolotl, perspectivismo, devir-animal, incompletude, ser-com

O pensamento sobre o animal é um pensamento sobre a alteridade em sua diferença irredutível, em sua estranheza indomesticável; é também um pensamento sobre o ponto de vista do outro, sobre sua perspectiva em relação a mim. Nesse sentido, é um pensamento que coloca em jogo minha individualidade e meu antropocentrismo, trazendo à luz os limites do homem, seus limiares, suas fronteiras. Afinal, como nos ensina Jacques Derrida, não apenas é ao outro (humano ou inumano) que se deve fazer a pergunta sobre quem é este que eu sou, ${ }^{1}$ como também é a partir do outro-inumano que o eu-humano se coloca como categoria. ${ }^{2}$

Na ontologia ameríndia, essa ideia se torna práxis através do xamanismo e se espalha por todas as relações sociais, sejam elas entre humanos ou entre humanos e não humanos. Conforme anota a antropóloga Aparecida Vilaça, em seu estudo sobre os índios Wari, ${ }^{3}$ ao se

\footnotetext{
1 "Quem sou eu então? Quem é este que eu sou? A quem perguntar, senão ao outro? E talvez ao próprio gato?” (DERRIDA. O animal que logo sou, p. 18.)

2 "Como todo olhar sem fundo, como os olhos do outro, esse olhar dito 'animal' me dá a ver o limite abissal do humano: o inumano ou o a-humano, os fins do homem, ou seja, a passagem das fronteiras a partir da qual o homem ousa se anunciar a si mesmo, chamando-se assim pelo nome que ele acredita se dar.” (DERRIDA. O animal que logo sou, p. 31.)

${ }^{3}$ VILAÇA. O que significa tornar-se outro? Xamanismo e contato interétnico na Amazônia, p. 56-72.
} 
tornar animal, o xamã adota a perspectiva dos seres humanos e passa a ver os Wari como karawa, isto é, como não humanos. Dessa forma, ele permite a todos da sociedade "a experiência, indireta, de outro ponto de vista, o ponto de vista do inimigo”. Trata-se, conclui ela, de uma reflexão profunda sobre a humanidade, pois só nessa situação constantemente instável, “arriscando-se a viver sempre na fronteira entre o humano e o não humano”, sabendo o que é ser karawa, é que os Wari podem experimentar o que é realmente ser humano.

Isso é possível porque, explica Eduardo Viveiros de Castro, na concepção indígena (em especial das tribos de origem tupi-guarani), os animais são capazes de intencionalidade consciente, ou seja, de um ponto de vista, de uma perspectiva. Daí o antropólogo denominar perspectivismo a esse aspecto do pensamento ameríndio, segundo o qual "o mundo é habitado por diferentes espécies de sujeitos ou pessoas, humanas e não-humanas, que o apreendem segundo pontos de vista distintos”. ${ }^{4}$ Dizer, portanto, que animais são pessoas é dizer que são capazes de assumir a posição de sujeito. Afinal, elucida Viveiros de Castro, as palavras indígenas que costumam ser traduzidas por ser humano não denotam a humanidade como espécie natural, mas a condição social de pessoa. O termo "gente” é usado como pronome pessoal, como partícula dêitica, registrando o ponto de vista do sujeito que está falando; e sujeito, neste caso, é quem tem alma, quem é capaz de um ponto de vista. ${ }^{5}$

Tendo isso em vista, e considerando que a arte é o lugar onde, no "pensamento domesticado", 6 podemos perguntar quem somos ao outro, o lugar onde o homem pode se ver a partir da perspectiva do inumano, é que proponho ler “Axolotl”, de Julio Cortázar, como um conto sobre o ponto de vista do animal, ou seja, como um conto perspectivista. ${ }^{7}$ Nesse sentido, o texto cortazariano não seria fantástico porque fantasioso, mas porque mágico (na concepção xamânica do termo), afinal, ele não apenas tensiona a ordem do real e do ficcional, mas principalmente questiona nossas separações entre mundos, nossos conceitos estáticos e estabelecidos, nossas dicotomias identitárias. Ali, o valor fundamental é a troca, o ver pelo olhar do outro, e não a identidade, as classificações ou representações.

\footnotetext{
${ }^{4}$ VIVEIROS DE CASTRO. A inconstância da alma selvagem e outros ensaios de antropologia, p. 347.

${ }^{5}$ VIVEIROS DE CASTRO. A inconstância da alma selvagem e outros ensaios de antropologia, p. 372.

${ }^{6}$ Viveiros de Castro explica que, para Lévi-Strauss, a arte é uma espécie de reserva ecológica ou parque natural do pensamento selvagem no pensamento domesticado. (VIVEIROS DE CASTRO. A inconstância da alma selvagem e outros ensaios de antropologia, p. 488.)

${ }^{7}$ Publicado pela primeira vez em 1952 na revista Buenos Aires Literaria, o conto se tornou parte do livro Final del juego, de 1956.
} 
Em vez de nomear o animal, de representá-lo ou descrevê-lo, o texto se transforma ele mesmo em axolotl. ${ }^{8}$ Isso pode ser percebido, por exemplo, na inconstância de pontos de vista, na frequente instabilidade da voz narrativa, que passa do "eu” humano ao "eu” da salamandra, e na flexibilidade dos pronomes: a $1^{\mathrm{a}}$ pessoa do singular se torna $1^{\mathrm{a}}$ pessoa do plural, para, por fim, se transformar numa $3^{\mathrm{a}}$ pessoa do singular, que é o próprio narrador e numa $1^{\mathrm{a}}$ pessoa do singular, que é o narrador transformado em axolotl, ou, para sermos mais exatos, em um devir-axolotl do homem e em um devir-homem do axolotl.

Como um xamã, o narrador cruza as barreiras corporais e adota a perspectiva de uma outra subjetividade não humana: "Hubo un tiempo en que yo pensaba mucho en los axolotl. Iba a verlos al acuario del Jardin des Plantes y me quedaba horas mirándolos, observando su inmovilidad, sus oscuros movimientos. Ahora soy un axolotl”, 9 relata ele já nas primeiras linhas. Dessa maneira, coloca em jogo nossa racionalidade ocidental e nosso antropocentrismo, rompendo a lógica evolutiva e erguendo as bases de outra ontologia, na qual o outro inumano é pensado como alguém capaz de intencionalidade:

(...) vi a un axolotl junto a mí que me miraba, y supe que también él sabía, sin comunicación posible pero tan claramente. O yo estaba también en él, o todos nosotros pensábamos como un hombre (...)

Ahora soy definitivamente un axolotl, y si pienso como un hombre es sólo porque todo axolotl piensa como un hombre dentro de su imagen de piedra rosa. ${ }^{10}$

Num “esfuerzo por penetrar en lo impenetrable de sus vidas”, o narrador fica obcecado pelo olhar do axolotl, justamente porque seus olhos falam da presença de uma vida diferente, de outro ponto de vista:

Sus ojos, sobre todo, me obsesionaban. Al lado de ellos, en los restantes acuarios, diversos peces me mostraban la simple estupidez de sus hermosos ojos semejantes a los nuestros. Los ojos de los axolotl me decían de la presencia de una vida diferente, de otra manera de mirar. ${ }^{11}$

Como um canibal, o narrador devora o ponto de vista do outro ("ponto de vista que é talvez, o ângulo ideal de visão de si mesmo”, nos lembra Viveiros de Castro a partir de suas

\footnotetext{
${ }^{8}$ Neste trabalho, optei por manter a forma original, em vez do português axolote, seguindo a escolha feita por Cortázar no conto, que utiliza a versão nauatl em detrimento do espanhol ajolote.

${ }^{9}$ CORTÁZAR. Final del juego, p. 161.

${ }^{10}$ CORTÁZAR. Final del juego, p. 166.

${ }^{11}$ CORTÁZAR. Final del juego, p. 164.
} 
análises sobre a perspectiva do inimigo no ritual guerreiro araweté), ${ }^{12}$ e os axolotl, como agentes conscientes, devoram o olhar do narrador: “'Usted se los come con los ojos’, me decía riendo el guardián, que debía suponerme un poco desequilibrado. No se daba cuenta de lo que eran ellos los que me devoraban lentamente por los ojos, en un canibalismo de oro.” ${ }^{\text {„3 }} \mathrm{E}$ é nesse canibalismo de ouro, penetrando e deixando-se penetrar pelos olhos uns dos outros, que acontece uma verdadeira transmutação de perspectivas, uma dupla desterritorialização:

Mi cara estaba pegada al vidrio del acuario, mis ojos trataban una vez más de penetrar el misterio de esos ojos de oro sin iris y sin pupila. Veía de muy cerca la cara de un axolotl inmóvil junto al vidrio. Sin transición, sin sorpresa, vi mi cara contra el vidrio, la vi fuera del acuario, la vi del otro lado del vidrio. ${ }^{14}$

Isso não significa, no entanto, que o devir pressuponha uma continuidade homogênea entre homem e axolotl. Primeiro, porque isso desrespeitaria a ruptura abissal que há entre as diferentes espécies de viventes; ignoraria esse limite múltiplo, a imensa pluralidade das linhas divisórias. (E aqui cabe um pequeno parêntese para rememorar a lição de Derrida de que a questão não passa por apagar as distinções entre humanos e inumanos, antes, por remarcar as diferenças que foram apagadas ou negadas. Não há limite, mas limiares, fronteiras múltiplas, plurais. Conforme explica Viveiros de Castro, a partir do conceito de animismo, "não é tanto a idéia de que os animais são semelhantes aos humanos, mas sim a de que eles - como nós são diferentes de si mesmos (...). Se todos têm alma, ninguém é idêntico a si”). ${ }^{15}$

Segundo, porque não há equivalência entre dois termos, não há troca de identidades, simplesmente porque não há dois termos prévios, não há um eu ou um outro previamente dado, pois o eu é um “devir entre multiplicidades”, para usar a bela expressão de Deleuze e Guattari, ${ }^{16}$ um ser incompleto, que se realiza justamente no contato com o outro. É neste sentido que a figura do axolotl é decisiva. Como bem reparou Cortázar, esse simpático monstrinho, aparentemente tão distante de nós, diz muito mais sobre a incompletude do homem do que qualquer outro animal.

\footnotetext{
${ }^{12}$ VIVEIROS DE CASTRO. A inconstância da alma selvagem e outros ensaios de antropologia, p. 281.

${ }^{13}$ CORTÁZAR. Final del juego, p. 165.

${ }^{14}$ CORTÁZAR. Final del juego, p. 166.

${ }^{15}$ VIVEIROS DE CASTRO. A inconstância da alma selvagem e outros ensaios de antropologia, p. 377. (grifos do autor)

${ }^{16}$ DELEUZE; GUATTARI. Devir-intenso, devir-animal, devir-impercetível, p. 33.
} 
Empecé viendo en los axolotl una metamorfosis que no conseguía anular una misteriosa humanidad. (...) No eran seres humanos, pero en ningún animal había encontrado una relación tan profunda conmigo. Los axolotl eran como testigos de algo. ${ }^{17}$

Esse algo que os axolotl testemunham é sua infância perene, seu eterno devir, sua metamorfose que nunca se completa. Digo isso porque o Ambystoma mexicanum, nome científico do nosso personagem, não se desenvolve da fase de larva, conservando durante toda a vida características típicas do estado larval das salamandras, como brânquias externas e barbatanas que vão da cabeça à ponta do rabo. Raramente (quase nunca na natureza) o axolotl sofre metamorfose para se tornar adulto, mesmo assim é totalmente capaz de se reproduzir e de transmitir essa forma juvenil a sua prole, se desdobrando numa nova espécie.

Todavia o estudo dessa retenção de características infantis na maturidade, chamada neotenia, foi muito além do axolotl e da própria zoologia. O fenômeno foi pensado, já na década de 1020, por Louis Bolk como uma nova chave para entender a evolução humana. Segundo o anatomista holandês, o homem é "um feto de primata que amadureceu sexualmente", ${ }^{18}$ um ser prematuro incapaz de se desfazer dos sinais fetais, mesmo assim, apto à reprodução e à transmissão desses caracteres juvenis.

Na ficção, o tema apareceu pela primeira vez em 1942 com Aldous Huxley, cujo irmão mais velho, o biólogo darwinista Julian Huxley, realizava importantes pesquisas sobre a metamorfose tardia de anfíbios ${ }^{19}$ (provavelmente, dos axolotl). No livro After many a summer dies a swan, o autor de Admirável mundo novo reserva um final surpreendente à história de Jo Stoyte, um magnata da indústria petrolífera norte-americana que tem pavor da morte. Obcecado pela ideia de viver eternamente, Stoyte financia a pesquisa do doutor Obispo, que procurava a saída para a longevidade humana em carpas centenárias. Após descobrir que, no século 18, o conde de Gonister tinha antecipado suas descobertas ao se alimentar das tripas cruas desses peixes e obter resultados incríveis, o médico viaja à Inglaterra e encontra o conde vivo com 201 anos, metamorfoseado "num feto de macaco que teve tempo de crescer". ${ }^{20}$ Esclarece o doutor:

Marcha do desenvolvimento retardada... um dos mecanismos da evolução... quanto mais velho um antropóide, mais estúpido... senilidade e

\footnotetext{
${ }^{17}$ CORTÁZAR. Final del juego, p. 165.

${ }^{18}$ Citado por GOULD. Darwin e os grandes enigmas da vida, p. 59.

${ }^{19}$ GOULD. Darwin e os grandes enigmas da vida, p. 59.

${ }^{20}$ HUXLEY. Também o cisne morre, p. 344.
} 
envenenamento por esteróis... (...) mas enquanto isto o antropóide fetal podia atingir a maturidade... Enfim, a melhor pilhéria do mundo!”21

Se considerarmos essa premissa verdadeira, o homem estaria para o primata da mesma forma que o axolotl para a salamandra. Isso explicaria, nos mostra Giorgio Agamben, as “particularidades morfológicas do homem que, da posição do furo occipital à forma da concha da orelha, da pele glabra à estrutura das mãos e dos pés, não correspondem às dos antropóides adultos, mas às dos seus fetos". 22 Isso explicaria também o longo tempo que os seres humanos levam para completar o desenvolvimento de alguns atributos que possuem apenas em potência no momento que nascem. Entre esses atributos, um dos mais determinantes seria a própria linguagem, visto que, diferente dos outros animais, o homem não é desde sempre falante.

E é na linguagem, ou melhor, na falta dela, que Agamben irá se ater em "Ideia da Infância”. Nesse pequeno texto publicado no livro Idéia da prosa, ele defende a tese de que, enquanto os animais rejeitam as possibilidades somáticas que não estão inscritas em seu gérmen, o ser humano, abandonado a sua própria infância, estaria em condições de dar atenção ao que não está escrito no seu código genético. Essa criança neotênica ficaria fora de si num mundo, porquanto “estaria, verdadeiramente, à escuta do ser”. ${ }^{23} \mathrm{O}$ problema é que essa abertura não é um evento que possa permanecer em sua memória genética, “mas antes qualquer coisa que terá de permanecer exterior, que não lhe diz respeito e que, como tal, só pode ser confiada ao esquecimento", ${ }^{24}$ um nada que antecipa toda a presença e toda a memória. É por conta disso que o homem precisa transmitir sua própria distração, antes de transmitir qualquer conhecimento; precisa transmitir a linguagem, antes de falar. Superar esta ausência de voz, apreender este inapreensível e tornar adulta esta eterna criança é, segundo Agamben, o que tentam as diversas nações e as muitas línguas históricas. Somente no dia em que assumirmos essa infância é que seremos capazes de construir uma história e uma língua universais, conclui o pensador italiano, acrescentando que "este autêntico apelo da humanidade em relação ao soma infantil tem um nome: o pensamento, ou seja a política”. ${ }^{25}$

Poucos anos depois, em 1989, no prefácio da edição francesa de Infância e História, o mesmo Agamben volta ao assunto para dizer que a infância a que se refere não é um lugar

\footnotetext{
${ }^{21}$ HUXLEY. Também o cisne morre, p. 346.

${ }^{22}$ AGAMBEN. Idéia da prosa, p. 91.

${ }^{23}$ AGAMBEN. Idéia da prosa, p. 92.

${ }^{24}$ AGAMBEN. Idéia da prosa, p. 93.

${ }^{25}$ AGAMBEN. Idéia da prosa, p. 95.
} 
cronológico ou uma idade psicossomática, mas um experimentum linguae, uma experiência com a linguagem na sua pura autorreferencialidade, sem transcendente. Esse experimentum seria, portanto, a experiência da própria língua, da própria faculdade ou potência de falar, uma tentativa de nominar conceitos vazios, ou seja, um pensamento. Aliás, para Agamben, é provável que "aquilo que chamamos de pensamento seja puramente e simplesmente este experimentum linguae". ${ }^{26}$ Buscar uma pólis e uma oikía que estejam à altura dessa comunidade vazia e impresumível que nasce no experimentum linguae seria justamente a tarefa infantil da humanidade que vem, ${ }^{27}$ levando o homem a uma revisão radical da própria ideia de um Comum.

Ainda seguindo a pista da neotenia, a partir do conto de Cortázar, Dany-Robert Dufour defende a ideia de que o homem é um axolotl que se ignora, ${ }^{28}$ já que, como o axolotl, o ser humano é um animal que não conseguiu ser animal verdadeiramente, ou seja, não se tornou um animal adulto, acabado, consumado, finalizado. Tanto eles quanto nós apresentamos, portanto, a particularidade de não sermos finitos (finis), de sermos in-finitos. É isso, analisa o filósofo francês, que o narrador de Cortázar quer dizer quando afirma que os axolotl não são animais:

Y sin embargo estaban cerca. Lo supe antes de esto, antes de ser un axolotl. Lo supe el día en que me acerqué a ellos por primera vez. Los rasgos antropomórficos de un mono revelan, al revés de lo que cree la mayoría, la distancia que va de ellos a nosotros. La absoluta falta de semejanza de los axolotl con el ser humano me probó que mi reconocimiento era válido, que no me apoyaba en analogías fáciles. (...) Yo creo que era la cabeza de los axolotl, esa forma triangular rosada con los ojillos de oro. Eso miraba y sabía. Eso reclamaba. No eran animales. $^{29}$

Para Dufour, esse inacabamento orgânico do homem se supre com uma experiência decisiva no processo de formação do indivíduo, afetando o campo da subjetividade e da intersubjetividade. Tal experiência seria o último ato de maturidade natural e, ao mesmo tempo, o primeiro ato cultural que precipita decisivamente o sujeito no mundo humano.

Por tudo isso é que podemos concluir que, mais do que consequências biológicas, essa incompletude, essa in-finitude, essa infantilidade do homem implica consequências ontológicas e sociais, políticas e éticas, pois é justamente nesse inacabamento que nos

\footnotetext{
${ }^{26}$ AGAMBEN. Infância e história, p. 13.

${ }^{27}$ AGAMBEN. Infância e história, p. 17.

${ }^{28}$ DUFOUR. Lettres sur la nature humaine à l'usage des survivants.

${ }^{29}$ CORTÁZAR. Final del juego, p. 164. (grifo do autor)
} 
abrimos ao outro, entramos em contato, em contágio com o outro. Uma vez que precisamos absorver do outro aquilo que nos falta, ou seja, visto que é o outro quem tem a base da existência biológica, o desenvolvimento do eu se dá ao custo de uma perda da identidade que é a ascensão do outro na base da minha subjetividade. Nesse sentido é que a subjetividade não é um para si, mas um para o outro, desde seu início. ${ }^{30}$ Como nos lembra Emmanuel Lévinas, "bem antes da consciência e da escolha - antes que a criatura se reúna em presente e representação para se fazer essência - o homem aproxima-se do homem”, visto que "a humanidade do homem, a subjetividade, é uma responsabilidade pelo outro".31 Responsabilidade essa que dilacera toda a essência, pois a própria identidade do eu humano é definida a partir dela: “Eu, não intercambiável, sou eu apenas na medida em que sou responsável”, conclui Lévinas. ${ }^{32}$ Essa responsabilidade significa, antes de tudo, a deposição do eu soberano na consciência de si e na relação com outrem. Daí que, para o autor de Humanismo do outro homem, a ética é o espaço onde se dá o próprio nó do subjetivo. ${ }^{33}$ Afinal, só chegamos a uma consciência de nós mesmos através de outros seres viventes (humanos ou animais), através de nossa responsabilidade por eles, através do embate ético que essa relação propicia.

Está aí a base do eu e de sua relação com o mundo, está aí também a raiz da amizade, já que, como esclarece Agamben, “a amizade é a condivisão que precede toda divisão, porque aquilo que há para repartir é o próprio fato de existir, a própria vida. E é essa partilha sem objeto, esse com-sentir originário que constitui a política.”34 Mas essa partilha não significa consenso, pelo contrário, conforme explica Jean-Luc Nancy, no contato, no estar-junto, não há fusão, apenas turbulência. O axolotl não se torna um homem e nem o homem se torna axolotl; enquanto existentes, homem e axolotl co-existem, porquanto existir é sempre coexistir, ex-istir, existir para fora, para o outro. Na perspicaz análise de Nancy, ${ }^{35}$ a essência da existência humana está no ex (Heidegger a escreve “ek-sistence”), como exílio do eu na exterioridade, na alteridade e na alteração. O eu como abertura e saída para o outro. E se, como afirma Aristóteles, “existir significa, de fato, sentir e pensar”, ${ }^{36}$ é porque esse existir,

\footnotetext{
${ }^{30}$ LÉVINAS. Ética e infinito, p. 80.

${ }^{31}$ LÉVINAS. Humanismo do outro homem, p. 105.

${ }^{32}$ LÉVINAS. Ética e infinito, p. 84.

${ }^{33}$ LÉVINAS. Ética e infinito, p. 79.

${ }^{34}$ AGAMBEN. O que é o contemporâneo? e outros ensaios, p. 92.

${ }^{35}$ NANCY. La existencia exiliada, p. 34-39.

${ }^{36}$ Citado por AGAMBEN. O que é o contemporâneo? e outros ensaios, p. 87.
} 
co-existir, é sempre co-sentir e co-pensar. É pensar junto, é partilhar um pensamento ou um sentimento, é, portanto (já vimos com Agamben), fazer política.

Na medida em que, como o axolotl, o ser humano não é ser completo, mas larva perene, um entre, cuja forma é a forma do inacabável, sem origem ou destino, é que é capaz de devir. Como ser-com, ou seja, como ser que circula no com e como o com desta "coexistencia singularmente plural”, ${ }^{37}$ o homem precisa assumir sua neotenia, sua incompletude, questionando a si mesmo como coisa separada, formada, isolada. Mais que isso, precisa de com-paixão, no sentido que Nancy dá ao termo, ou seja, do contato dos seres-uns-com-osoutros. "Ni altruismo, ni identificación: la sacudida de la brutal contigüidad.”38 Precisa de uma ontologia do ser-com, que mantenha juntas as esferas da natureza e da história, do humano e do não humano, uma ontologia para o mundo, uma ontologia de seres abertos ao mundo, seres com, no e pelo mundo. Essa é a tarefa neotênica do homem. A tarefa que o axolotl nos ensina.

\begin{abstract}
In giving itself to the other's point of view, in the becoming-animal of the human and the becoming-human of the animal, "Axolotl”, by Julio Cortázar, questions our identitary dichotomies and exposes our incompleteness, the being-with that we are, the Self as a becoming between two multiplicities.
\end{abstract}

\title{
KEYWORDS
}

Axolotl, perspectivism, becoming-animal, incompleteness, being-with

\section{REFERÊNCIAS}

AGAMBEN, Giorgio. Idéia da prosa. Trad. João Barrento. Lisboa: Edições Cotovia, 1999.

AGAMBEN, Giorgio. Infância e história. Trad. Henrique Burigo. Belo Horizonte: Editora UFMG, 2005.

AGAMBEN, Giorgio. O que é o contemporâneo? e outros ensaios. Trad. Vinícius Nicastro Honesko. Chapecó: Argos, 2009.

CORTÁZAR, Julio. Final del juego. Buenos Aires: Punto de Lectura, 2007.

\footnotetext{
${ }^{37}$ NANCY. Ser singular plural, p. 19.

${ }^{38}$ NANCY. Ser singular plural, p. 12.
} 
DELEUZE, Gilles; GUATTARI, Félix. Devir-Intenso, Devir-Animal, Devir-Imperceptível. In:__ Mil platôs: capitalismo e esquizofrenia.. Trad. Suely Rolnik. São Paulo: Ed. 34, 1997. v. 4. p. 10-114.

DERRIDA, Jacques. O animal que logo sou. Trad. Fábio Landa. São Paulo: Editora UNESP, 2002.

DUFOUR, Dany-Robert. Lettres sur la nature humaine à l'usage des survivants. Paris: Calmann-Lévy, 1999.

GOULD, Stephen Jay. Darwin e os grandes enigmas da vida. Trad. Maria Elizabeth Martinez. São Paulo: Martins Fontes, 1999.

HUXLEY, Aldous. Também o cisne morre. Trad. Paulo Moreira da Silva. São Paulo: Editora Globo, 2002.

LÉVINAS, Emmanuel. Ética e infinito. Trad. João Gama. Lisboa: Edições 70, 2007.

LÉVINAS, Emmanuel. Humanismo do outro homem. Organização e tradução Pergentino S. Pivatto. Petrópolis: Vozes, 2009.

NANCY, Jean-Luc. La existencia exiliada. Archipiélago, Barcelona, n. 26-27, 1996.

NANCY, Jean-Luc. Ser singular plural. Trad. Antonio T. Sancho. Madrid: Arena Libros, 2006.

VILAÇA, Aparecida. O que significa tornar-se outro? Xamanismo e contato interétnico na Amazônia. Revista Brasileira de Ciências Sociais, v. 15, n. 4, p. 56-72, 2000.

VIVEIROS DE CASTRO, Eduardo. A inconstância da alma selvagem e outros ensaios de antropologia. São Paulo: Cosac Naify, 2002. 